\title{
The Importance of Learning Health Systems in Addressing the Opioid Crisis
}

\author{
Wilson M. Compton, MD, MPE®, Tisha Wiley, PhD, and Carlos Blanco, MD, PhD
}

National Institute on Drug Abuse, National Institutes of Health, U.S. Department of Health and Human Service, Bethesda, MD, USA.

Interventions and research to address the US opioid crisis have, for the most part, targeted opioid use, misuse, and addiction specifically. While such a focus can lead to useful innovations in the care of opioid use disorder, the fact that many persons with opioid use disorder use multiple substances (both over their life course and simultaneously in drug-using episodes) makes it imperative to address broader issues of addiction in persons who have opioid use disorder as their presenting concern. Because of integrated care and the ability to target multiple clinical concerns in parallel, the Veterans Administration (VA) may be uniquely situated to address the key issue of multi-morbidity that persons with opioid use disorder so frequently exhibit. Research at the VA can build on new interventions developed by the National Institutes of Health (and others) and can help to determine the best ways to implement these interventions. Research at the VA does not need to duplicate efforts supported by other funders but can complement such work by providing an integrated platform for determining the best approaches to implementing innovations. The real-world learning health system that has been developed in the VA is poised to contribute in just such important ways.

J Gen Intern Med 35(Suppl 3):S891-S4

DOI: $10.1007 / \mathrm{s} 11606-020-06267-2$

() Society ofGeneral InternalMedicine (This is aU.S. government work and not under copyright protection in the U.S.; foreign copyright protection may apply) 2020

\section{INTRODUCTION}

The US opioid crisis continues to exert a major impact on health and social outcomes. Over the last 15 years, deaths due to opioid overdoses exceed $400,000^{1}$ and declines in overall US life expectancy are at least partly explained by this increase in overdose mortality. ${ }^{2,3}$ Morbidity caused by opioids includes increasing infectious disease (particularly HIV, hepatitis, and endocarditis), sleep disorders, affective disorders, and increasing neonatal opioid withdrawal, among other outcomes. ${ }^{4-8}$ Overall economic impact from opioid misuse was estimated at $\$ 500$ billion per year in $2017 .^{9}$ In response, prevention and treatment practices and policies have been expanded, although gaps remain. ${ }^{5}$ These include increasing access to medications for opioid use disorder, ${ }^{10-12}$ reducing

Received August 13, 2020

Accepted September 21, 2020

Published online November 3, 2020 opioid prescribing, ${ }^{13-15}$ increasing access to naloxone, ${ }^{16,} 17$ improving public health surveillance, ${ }^{13}$ increasing access to harm reduction programs such as syringe services, ${ }^{13}, 18,19$ and major investments in research. ${ }^{20,21}$

The Veterans Administration (VA) with its health care system, the Veterans Health Administration, has an exceptional ability to address these opioid issues by bringing to bear integrated health and social services. But how can these programs maximize their impact? Are there outside research and health services developments that can complement the innovative programs implemented by the VA? We suggest that several areas of work and developments outside the VA might be considered resources to help. Furthermore, linkages of VA- and non-VA-supported research may lead to greater impact than either group alone.

In this commentary, we highlight the following: (1) developments in the opioid crisis including the prominence of synthetic opioids in recent years and a shift to stimulants, especially methamphetamine, as major contributors to overdose mortality; (2) an evolving focus on learning health systems as a goal both for short- and long-term solutions; and (3) a focus on major research efforts inside and outside of the VA that could be relevant to the care of veterans and non-veterans.

\section{DEVELOPMENTS IN THE OPIOID CRISIS}

Although involving compounds very similar in their pharmacologic properties, the opioid crisis in the USA is better conceptualized as two sets of intertwined issues noted since about the year 2000: misuse of and addiction to prescription opioid analgesics, which predominated in the first decade of the crisis, and, during the second decade, use of and addiction to illicit opioids. ${ }^{5}$ Thus, the first wave of the opioid crisis refers to overdose deaths related primarily to prescription-type opioids, and the second wave refers to heroin as the predominant illicit opioid. However, within the rubric of illicit opioid use, a further distinction can be drawn between the resurgent use of heroin and the problem of both deliberate and unintentional use of even more potent synthetic opioid drugs (namely, illicitly made fentanyl and its analogs). ${ }^{5}$ A rapid rise in deaths involving these synthetic opioids, beginning in 2013, marked the third wave of the opioid crisis. ${ }^{5}$ From 2010 to 2018, deaths from fentanyl and other synthetic opioids increased nearly tenfold, from around 3007 (14.3\% of opioid-related deaths) to $28,466(59.8 \%) .{ }^{1,5}$ 


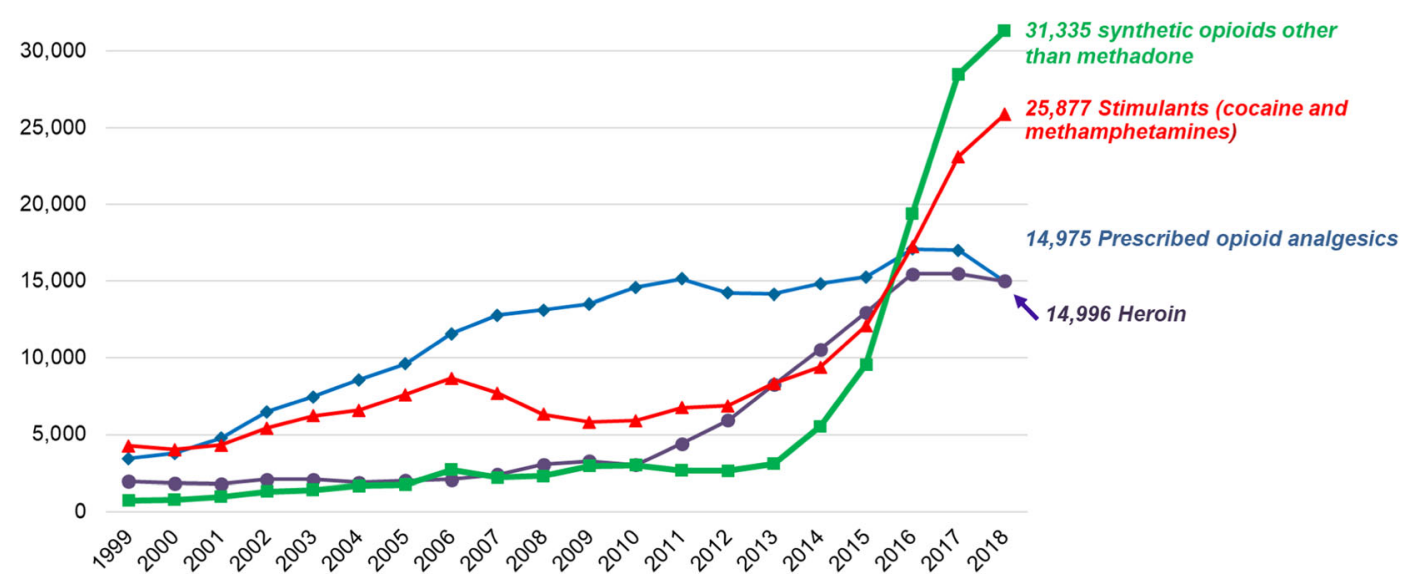

Figure 1 Overdose deaths from 1999 to 2018 for prescription-type opioid analgesics, heroin, synthetic opioids other than methadone (i.e., fentanyl-related compounds), and stimulants (methamphetamine and/or cocaine).

Use of stimulants, especially methamphetamine, has also recently expanded in many locations and is a major cause of morbidity and mortality as seen in the rising rates of stimulant-related overdose deaths over the past 5 years (Fig. 1). While opioids remain a major contributor to morbidity and mortality, the clinical issues presented by persons with opioid use disorder are not limited to this one class of substances. Persons with opioid use disorder very frequently use other substances, ${ }^{22,}{ }^{23}$ and these combinations may be particularly lethal, as seen in the synergy of opioids and sedating substances such as alcohol and benzodiazepines. ${ }^{24,25}$ Even the combination of opioids and methamphetamine may cause synergistic lethality, as suggested by preclinical research, ${ }^{26}$ in addition to the expected toxicity of each substance itself. Research on the impact of co-administration of opioids and methamphetamine (and other combinations of substances) needs both basic and applied approaches in order to maximize the ability to treat patients who use such complicated combinations of substances.

Overall, persons with opioid use disorder experience a broad range of clinical needs with major impacts on their health outcomes, including polydrug use as well as issues related to legal, housing, mental illness, employment, and family domains. ${ }^{22,}{ }^{23}$ Because of this, the opioid specificity of current interventions may limit their ability to address the broader problems of persons with opioid use-related problems. One advantage for the VA in responding to these broad issues is the ability to implement effective treatments into the system of care. For instance, the VA has been able to implement contingency management therapies into routine clinical care. ${ }^{27}$ By contrast, non-VA Medicaid supported treatment has not been able to implement contingency management due to concerns about payments to patients. ${ }^{28}$ Yet, such care is one of the few treatments to show an impact on methamphetamine ${ }^{29}$ and the lack of uptake outside of the VA remains a major concern. ${ }^{28}$ This is an area where VA-led research may pave the way for care improvements for veterans and non-veterans alike.

\section{LEARNING HEALTH SYSTEMS}

An evolving theme in health care delivery research has been the focus on learning health systems as a goal both for short- and long-term solutions, and the VA has been highlighted as an exemplar of a learning health system. ${ }^{30}$ Learning health systems are designed to address organizational and process of care-related weaknesses in treatment systems. Rather than targeting discrete practices for individual improvements, a learning health system is inherently designed for continuous quality assessment and improvement. Key elements that can facilitate such a progressive system are as follows: integrated health records, seamless links of different levels of care, reduction of financial barriers to care access, and integrated clinical practices. All of these exist in the VA at the present time because of years of innovation and visionary leadership. Such systems can facilitate testing of novel practice improvements that may have implications for both veteran and non-veteran populations. Even so, research within the VA setting has helped to demonstrate that a learning healthcare system must always attend to data in order to ensure that performance gains are sustained over time. The VA provides a unique platform for understanding how to sustain and build on improvements overtime across an entire system of care. ${ }^{30,31}$

\section{MAJOR OPIOID RESEARCH EFFORTS}

A focus on major research efforts outside of the VA also could be useful to the care of veterans. Relevant research that is outside of VA includes especially the National Institutes of Health's Helping to End Addiction Long-term (HEAL) program. ${ }^{21}$ Within HEAL, of particular relevance to opioid crisis efforts at the VA are the expanded medication development programs that could lead to new treatments for all with opioid use disorder, including veterans. ${ }^{32}$ HEAL also includes services research to expand access to effective treatments for opioid use disorder which also may provide useful approaches 
to improve the care of veterans. These include efforts targeting general medical settings and large-scale systematic efforts focused on criminal justice settings, the Justice Community Opioid Innovation Network. ${ }^{32}$

Of potential relevance to the NIH-supported program of research in criminal justice settings is the veteran-specific use of Veterans Justice Outreach Specialists. Veterans with justice involvement are particularly vulnerable to negative health outcomes, ${ }^{33}$ and are less likely to receive medications for opioid use disorder than their non-justice-involved counterparts. ${ }^{34}$ Veterans Justice Outreach Specialists proactively seek to identify veterans who are justice-involved and advocate on their behalf, for example helping them to connect to veteran drug courts or services such as housing, healthcare, or addiction and mental health treatment. While Veterans Justice Outreach Specialists do not single out veterans with opioid use disorder for intervention, the approach may be broadly applicable. Furthermore, outside of the VA, we are aware of no other example of such a role embedded within the medical or treatment system. This kind of system-spanner role focused specifically on the needs of the most vulnerable veteran populations is innovative and should be tested more robustly, including adaptations to work with those outside of the veteran context.

Much research supported by the National Institutes of Health is particularly focused on advancing basic science. In addition, National Institutes of Health studies reach more heterogenous populations than VA research programs as well as populations unlikely to be the focus of the VA research, including children/adolescents and nonveteran justice-involved persons. While the VA supports basic research, where the VA has particular and often unique strengths is in the area of health care system research. ${ }^{30}$ The VA's large, integrated system of care provides clear opportunities for studying implementation of innovations. The VA may be particularly suited to study variation while at the same constraining it. Of course, there are many areas of shared strength and for many basic and clinical studies, VA- and non-VAsupported work can both be important. In these areas, careful coordination to avoid inefficient duplication and enhance synergies is essential.

\section{CONCLUSIONS}

Interventions and research to address the US opioid crisis have, for the most part, targeted opioid use, misuse, and addiction specifically. While such a focus can lead to useful innovations in the care of opioid use disorder, the fact that many (and perhaps most) persons with opioid use disorder use multiple substances (both over their life course and simultaneously in specific drug-using episodes) makes it imperative to address broader issues of addiction in persons who have opioid use disorder as their presenting concern. Because of integrated care and the ability to target multiple clinical concerns in parallel, the VA may be uniquely situated to address the key issue of multi-morbidity that persons with opioid use disorder so frequently exhibit. Research at the VA can build on new interventions developed by other groups and can help to determine the best ways to implement these interventions. Research at the VA does not need to duplicate efforts supported by the National Institutes of Health (and other funders) but can complement such work by providing an integrated platform for determining the best approaches to implementing innovations. The real-world learning health system that has been developed in the VA is poised to contribute in just such important ways.

Corresponding Author: Wilson M. Compton, MD, MPE; National Institute on Drug Abuse, National Institutes of Health, U.S. Department of Health and Human Service, Bethesda, MD, USA (e-mail: wcompton@nida.nih.gov).

\section{Compliance with Ethical Standards:}

Conflict of Interest: W.M.C. reports ownership of stock in General Electric, 3 M, and Pfizer Inc. unrelated to the submitted work. Other authors have no interests to declare.

Disclaimers: The opinions expressed in this paper are those of the authors and do not necessarily reflect the views of the National Institute on Drug Abuse of the National Institutes of Health, or the U.S. Department of Health and Human Services.

\section{REFERENCES}

1. Hedegaard H, Miniño AM, Warner M. Drug overdose deaths in the United States, 1999-2018. NCHS Data Brief, no 356. Hyattsville, MD: National Center for Health Statistics. 2020.

2. Case A, Deaton A. Mortality and morbidity in the 21 st century. Brook Pap Econ Act 2017;397-476.

3. Dowell D, Arias E, Kochanek K, Anderson R, Guy GP, Losby J, et al. Contribution of opioid-involved poisoning to the change in life expectancy in the United States, 2000-2015. JAMA 2017;318(11):1065-1067.

4. Cranston K, Alpren C, John B, Dawson E, Roosevelt K, Burrage A, et al. Notes from the field: HIV diagnoses among persons who inject drugs - Northeastern Massachusetts, 2015-2018. Morb Mortal Wkly Rep 2019;68(10):253-254.

5. Compton WM, Jones CM. Epidemiology of the U.S. opioid crisis: the importance of the vector. Ann N Y Acad Sci 2019;1451(1):130-143.

6. Ko JY, Patrick SW, Tong VT, Patel R, Lind JN, Barfield WD. Incidence of neonatal abstinence syndrome - 28 States, 1999-2013. MMWR 2016;65:799-802.

7. Zibbell JE, Asher AK, Patel RC, Kupronis, Iqbal BK, Ward JW, et al. Increases in acute hepatitis $\mathrm{C}$ virus infection related to a growing opioid epidemic and associated injection drug use, United States, 2004 to 2014. Am J Public Health. 2018;108(2):175-181.

8. Jackson KA, Bohm MK, Brooks JT, Asher A, Nadle J, Bamberg, et al. See I. Invasive methicillin-resistant staphylococcus aureus infections among persons who inject drugs - six sites, 2005-2016. MMWR 2018;67(22):625-628.

9. Council on Economic Advisers. The Underestimated Cost of the Opioid Crisis. 2017. Available at: https://www.whitehouse.gov/sites/whitehouse.gov/files/images/The $\% 20$ Underestimated $\% 20$ Cost $\% 20$ of $\% 20$ the\%20Opioid\%20Crisis.pdf. Accessed July 29, 2020.

10. Jones CM, Campopiano M, Baldwin G, McCance-Katz EF. National and state treatment need and capacity for opioid agonist medicationassisted treatment. Am J Public Health 2015;105(8):55-63.

11. Jones CM, McCance-Katz EF. Characteristics and prescribing practices of clinicians recently waivered to prescribe buprenorphine for the treatment of opioid use disorder. Addiction 2019;114(3):471-482. 
12. National Academies of Science, Engineering, and Medicine. 2019. Medications for Opioid Use Disorder Save Lives. Washington, DC: National Academies Press.

13. Centers for Disease Control and Prevention. Evidence-based strategies for preventing opioid overdose: what's working in the United States. National Center for Injury Prevention and Control, Centers for Disease Control and Prevention, U.S. Department of Health and Human Services, 2018. Available from http://www.cdc.gov/drugoverdose/pdf/pubs/2018-evidence-based-strategies.pdf. Accessed July 29, 2020.

14. Compton WM, Wargo EM. Prescription drug monitoring programs: promising practices in need of refinement. Ann Intern Med 2018;168:826-827.

15. Dowell D, Haegerich TM, Chou R. CDC guideline for prescribing opioids for chronic pain - United States, 2016. MMWR 2016;65(1):1-49.

16. Jones CM, Lurie PG, Compton WM. Increase in naloxone prescriptions dispensed in US retail pharmacies since 2013. Am J Public Health 2016;106(4):689-690.

17. Walley AY, Green TC. Mainstreaming naloxone through coprescription to patients receiving long-term opioid therapy for chronic pain. Ann Intern Med 2016;165(4):292-293.

18. Des Jarlais DC, Nugent A, Solberg A, Feelemyer J, Mermin J Holtzman D. Syringe service programs for persons who inject drugs in urban, suburban, and rural areas-United States, 2013. MMWR 2015;64(48): 1137-1141.

19. MacArthur GJ, Van Velzen E, Palmateer N, Kimber J, Pharris A, Hope $\mathbf{V}$, et al. Interventions to prevent HIV and Hepatitis $\mathrm{C}$ in people who inject drugs: a review of reviews to assess evidence of effectiveness. Intl $J$ Drug Policy 2014;25(1):34-52.

20. Fast Track Action Committee on Health Science and Technology Response to the Opioid Crisis of the Committee on Science, National Science and Technology Council. Health research and development to stem the opioid crisis: a national roadmap. 2019. Available at: https://www. whitehouse.gov/wp-content/uploads/2019/10/Health-Research-andDevelopment-for-Opioid-Crisis-National-Roadmap-2019.pdf. Accessed July 29, 2020.

21. Collins FS, Koroshetz WJ, Volkow ND. Helping to end addiction over the long-term: the research plan for the NIH HEAL Initiative. JAMA 2018;320(2):129-130.

22. Han B, Compton WM, Blanco C, Jones CM. Correlates of prescription opioid use, misuse, use disorders, and motivations for misuse among US adults. J Clin Psychiatry. 2018;79(5):17m11973.

23. Jones CM, Logan J, Gladden RM, Bohm MK. Vital signs: demographic and substance use trends among heroin users - United States, 20022013. MMWR Morb Mortal Wkly Rep. 2015; 64(26):719-725.
24. Jones CM, McAninch JK. Emergency department visits and overdose deaths from combined use of opioids and benzodiazepines. Am $J$ Prev Med. 2015;49(4):493-501.

25. Jones CM, Einstein E, Compton WM. Changes in synthetic opioid involvement in drug overdose deaths in the United States, 2010-2016. JAMA. 2018;319(17):1819-1821.

26. Namiki M, Mori T, Sawaguchi T, Ito S, Suzuki T. Underlying mechanism of combined effect of methamphetamine and morphine on lethality in mice and therapeutic potential of cooling. J Pharmacol Sci. 2005;99(2):168-176

27. Petry NM, DePhilippis D, Rash CJ, Drapkin M, McKay JR. Nationwide dissemination of contingency management: the Veterans Administration initiative. Am J Addict. 2014;23(3):205-210

28. Petry NM. Contingency management treatments: controversies and challenges. Addiction. 2010 Sep; 105(9): 1507-1509

29. Ronsley C, Nolan S, Knight R, Hayashi K, Klimas J, Walley A, Wood E, Fairbairn N. Treatment of stimulant use disorder: a systematic review of reviews. PLoS One. 2020;15(6):e0234809.

30. Atkins D, Kilbourne AM, Shulkin D. Moving from discovery to systemwide change: the role of research in a learning health care system: experience from three decades of health systems research in the Veterans Health Administration. Annu. Rev. Public Health 2017;38:467-87

31. Finlay, A. K., Binswanger, I. A., Timko, C., Smelson, D., Stimmel, M. A., Yu, M., ... Harris, A. H. S. (2018). Facility-level changes in receipt of pharmacotherapy for opioid use disorder: Implications for implementation science. J Subst Abuse Treat, 95, 43-47. https://doi.org/10.1016/j. jsat.2018.09.006

32. National Institutes of Health. The helping to end addiction long-term initiative. Available at: https://heal.nih.gov/ Accessed July 29, 2020.

33. Finlay, A. K., Owens, M. D., Taylor, E., Nash, A., Capdarest-Arest, N., Rosenthal, J., ... \& Timko, C. (2019). A scoping review of military veterans involved in the criminal justice system and their health and healthcare. Health \& justice, 7(1), 6.

34. Finlay AK, Harris AH, Rosenthal J, Blue-Howells J, Clark S, McGuire $\mathbf{J}$, et al. Receipt of pharmacotherapy for opioid use disorder by justiceinvolved U.S. Veterans Health Administration patients. Drug Alcohol Depend. 2016;160:222-6.

Publisher's Note: Springer Nature remains neutral with regard to jurisdictional claims in published maps and institutional affiliations. 